\title{
CONE AND POSSIBLE ROD COMPONENTS OF THE FAST PHOTOVOLTAGE IN THE FROG EYE: A NEW METHOD OF MEASURING CONE REGENERATION RATES IN VIVO
}

\author{
JACK W. TAYLOR
}

Mental Health Research Institute, and the Department of Physics The University of Michigan, Ann Arbor, Michigan

(Received 29 July 1968; in revised form 24 September 1968)

\section{INTRODUCTION}

Electrical potentials produced by the eye or excised retina in the first few msec after an intense flash of light were discovered by BROWN and MURAKaMI (1964). The "Early Receptor Potential" or the Fast Photovoltage (FPV), as this response has been called by HaGINS and MCGAUGHY (1967), has been shown to be very probably produced by a molecular change in the rhodopsin or pigment molecules. Recent papers by CONE (1967) and PAK and Boes (1967) present evidence of the apparent molecular nature of the FPV and give references to earlier work. Early work included studies of rod and cone components of the FPV in all-rod animals (albino rats) and all-cone animals (Mexican ground squirrel) (CONE, 1964; PAK and EBrey, 1966), but not in an animal with both rods and cones. It therefore appeared interesting to study the FPV from a mixed rod-and-cone eye, to see if these components could be separated in the same eye. Frogs (Rana pipiens) were studied since they have been shown to contain at least three receptors, cones $\left(\lambda_{\max }\right.$ near $560 \mathrm{~nm}$ ), pink rods (containing rhodopsin) and green rods (blue absorbing) (GrANIT, 1941; DartNall, 1967; Donner and Rushton, 1959; Nilsson, 1964).

It seemed that it might be possible to separate rod and cone components of the FPV by comparing the FPV action spectrum in the dark-adapted state, after at least $12 \mathrm{hr}$ in the dark, and in the light-adapted state, after exposure to a continuous white light or a sequence of bright blue light flashes. Different rates of recovery after a bright bleaching light can also be used to separate rod and cone components, since it is known that frog rods take over an hour to regenerate (ZEWI, 1939), while cones (in humans) recover in a few minutes (Rushton, 1963; WeAle, 1959).

Since this study was started, B. Goldstern $(1967,1968)$ has published work on the FPV of an excised frog retina. He concludes that the FPV is predominately from the cones. He was also able to separate an apparent rod component and reports a recovery of the FPV in the excised retina considerably slower than reported here in vivo. The action spectra reported here do not agree with his at wavelengths below about $520 \mathrm{~nm}$. These differences will be discussed later.

1Parts of this study will be submitted in partial fulfillment of the requirements of the Doctor of Philosophy in the Horace H. Rackham School of Graduate Studies at the University of Michigan. 


\section{METHODS AND MATERIALS}

The apparatus and experimental arrangements have been described previously (EBREY and CONE, 1967). The living frogs were placed in a temperature-controlled chamber and were immobilized with $d$-tubocurarine chloride and $10 \%$ phenylephrine was dropped onto the dark-adapted eyes. The pupils were constricted to about $4 \mathrm{~mm}$ under these conditions. The eyelids were held open and contacts were made to the cornea with standard silver-silver chloride electrodes. An electrical response from the heartbeat was monitored (the preamplifier low frequency cutoff was set at $30 \mathrm{~Hz}$ to stabilize the oscilloscope trace). The excised retinas were mounted on a pad soaked in frog Ringer. Corning glass filters (CS series) and Baird Atomic narrow-band interference filters were used to isolate specific regions of the spectrum.

The amplitude of the FPV, at low pigment concentrations, can be taken as a relative measure of the number of unbleached pigment molecules present at the time of the flash, since as has been previously shown, the FPV is proportional to the number of molecules bleached by the flash (CONE, 1965). The amplitude of the FPV was measured from the first positive peak to the first negative peak (as indicated in the waveform in Fig. 3) to improve the reliability of the signal and reduce any errors due to a drift of the baseline. The FPV action spectra, or spectral sensitivities, were obtained by determining, as a function of wavelength, the relative intensity (number of quanta) needed to generate a constant amplitude FPV in

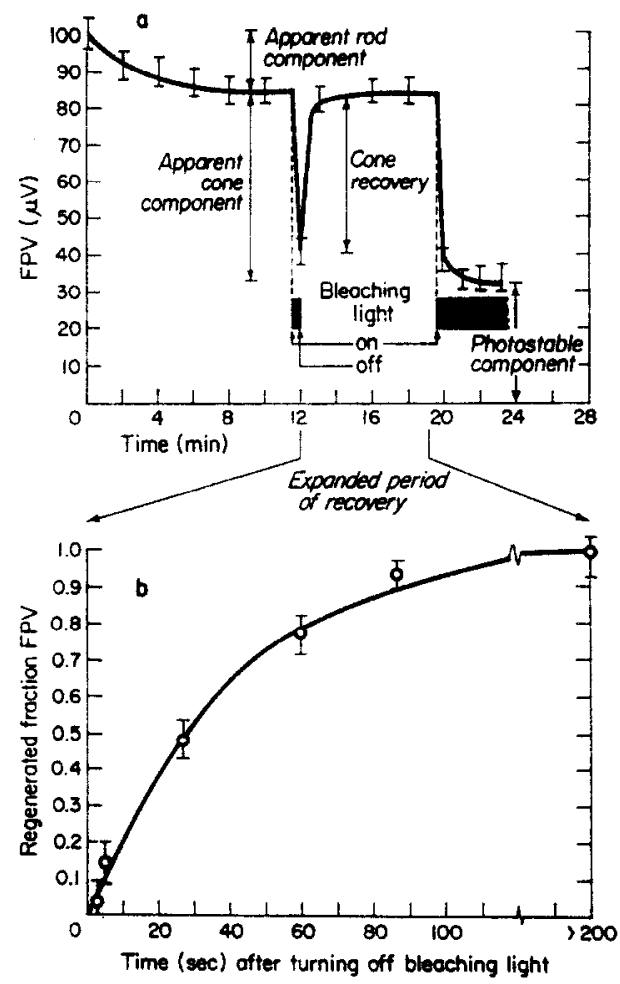

FIG. 1. (a) Typical FPV amplitudes (about $100 \mu \mathrm{V}$ ) from a sequence of flashes into the living eye of the frog, showing an initial small decrease; a large decrease caused by a strong bleach is followed by a rapid recovery of the amplitude in the dark. When the bleaching light is left on, a photostable component continues to be observed. The error bars represent the uncertainty of a single voltage measurement.

(b) Expansion of the apparent cone recovery section of Fig. 1a $(t=12$ to about $15 \mathrm{~min})$ in vivo. The fraction of the regenerable component of the FPV is plotted $v$. the time $t$ after turning off a strong bleaching light. Two data points were recorded per each complete recovery cycle, one at $t$ and the second at the end of the cycle (after about $200 \mathrm{sec}$ or more). This rapid recovery shows an apparent cone regeneration. The curve is the theoretical curve derived from a first-order rate equation, with a half-life of $27 \mathrm{sec}$ in this preparation (see text). 
the range of $20-50 \mu \mathrm{V}$. The sensitivity is the inverse of this relative intensity. The flash intensities at each wavelength were standardized using both a commercial Lite-Mike and a thermopile. All work presented here was done at about $22^{\circ} \mathrm{C}$.

\section{RESULTS}

A sequence of white flashes, near maximum intensity from a $60 \mathrm{~W}$ Strobonar Electronic Flash was directed into the dark-adapted frog eye in wivo and the FPV's were recorded. The light was focused through a beam splitter and condensing lens, and filtered to eliminate wavelengths about above $740 \mathrm{~nm}$ and below $410 \mathrm{~nm}$. The amplitude of the FPV decreased during the first few flashes, at two minute intervals, and leveled off at about 85 per cent of the original amplitude. See Fig. Ia.

If a strong continuous bleaching light (100-W lamp focused into the eye) is turned on for $30 \mathrm{sec}$, the FPV decreases further to about 30 per cent of its original amplitude. When the bleaching light is turned off, the FPV amplitude rises again, reaching in about 2 min the 85 per cent amplitude line. If the bleaching light is turned on and left on, a decrease to a constant photostable level, about $25-30$ per cent of the original is observed (Fig. 1a, right side). This photostable component of the FPV has been previously shown to be from the pigment epithelium (BROWN, 1965; EBREY and CONE, 1967). These results are observed both with and without a fixed pupil. These results could be accounted for by two hypotheses: (A) that the rapid recovery after the strong $30-\mathrm{sec}$ bleach might be from the regeneration of a cone pigment component which was bleached by the light and (B) that the initial small decrease (about 15 per cent) might be from a rod component that is bleached by the sequence of flashes and not regenerated during the 2-min dark intervals between flashes. ZEwI (1939) has shown that rhodopsin takes about an hour to regenerate in the living frog.

\section{APPARENT CONE REGENERATION}

To check the first hypothesis (A) it is possible to make two tests: (i) whether the regeneration of the FPV follows the expected first-order equation, as observed for human cones by RusHron (1963 and 1968); and (ii) whether the action spectrum of the lightadapted state agrees with known frog cone action spectra (GRANIT, 1941; ChAPMAN, 1961; GORDON, 1967; LIEBMAN, 1968).

To examine (i), the course of regeneration following the strong bleach was measured in the eye of the living frog (since neither a dead eye, or enucleated eye nor an excised retina showed as rapid regeneration as the live frog eye). The eye was light-adapted by a sequence of constant intensity white fiashes, as in Fig. 1a, and then the strong bleaching light was turned on for a given time interval, usually 10-30 sec. It was then turned off, and at a time $t$ later the same intensity white flash was presented and its FPV amplitude measured. This cycle could be repeated several times on a given eye with a different used to make the measurement after each strong bleach. Only one measurement flash was used after each bleach, since the flash itself bleaches a certain per cent of the pigment. The photostable component of the FPV for this eye was then determined using a long exposure to background light (as in Fig. 1a). By plotting the "regenerable" part of the FPV (this is, the total FPV minus the photostable amplitude) vs. $t$, a recovery curve was obtained such as shown in Fig. 1b. The smooth curve is a plot of a first-order rate equation $(1-F)=\exp (-0.69 t / \tau)$ when $F$ represents the regenerated fraction of the FPV, and it can be seen that the fit to the observed points is quite satisfactory. The half-life $\tau$ used 
for the smooth curve in Fig. $1 \mathrm{~b}$ is $27 \mathrm{sec}$. A group of seven other eyes gave a similar good fit to the numerical equation with half-lives in the range of $22 \pm 8 \mathrm{sec}$. Rushton (1963) measured the half-life for human cone regeneration and found it to be about $85 \mathrm{sec}$ at $37^{\circ} \mathrm{C}$, and his more recent work gives faster recovery rates (RusHron, 1968) under different conditions. WEALE (1959) obtained a total recovery time for human cones of 3-4 min.

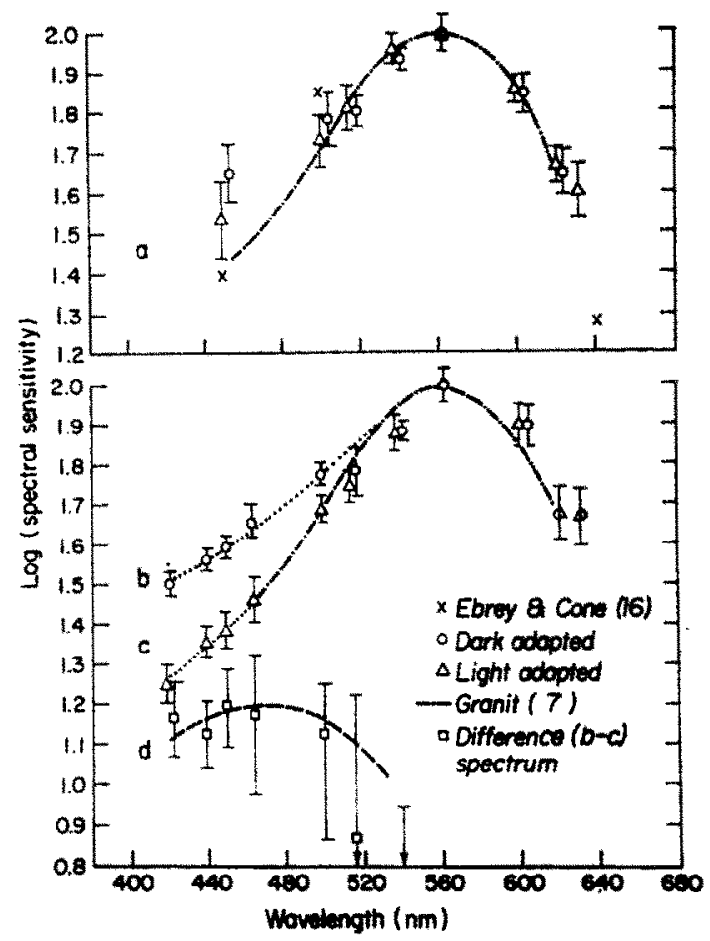

Fic. 2. (a) The dark-adapted and light-adapted action spectra of the live and enucleated frog eye (the same within experimental errors). The dot-dashed curve shows the cone (lightadapted) spectral sensitivity connected with "retinal spike frequency", as given by GRANT (1941). The data from BBRey and CONE (1967) represent the action spectrum of the positive peak of the FPY of an enucleated frog eye at $12^{\circ} \mathrm{C}$.

(b) The dark-adapted action spectra of the excised retina. The dotted curve was drawn through the points below $520 \mathrm{~nm}$.

(c) The light-adapted action spectra for the excised retina. The dot-dashed curve is again from GraNIT (1941), and the dotted line is a reasonable continuation through the data points. (d) The difference between the dark-adapted and light-adapted action spectra. The dashed curve is calculated from a sum of previously measured pink and green rod pigment spectral sensitivities (Darmall, 1953; DARmall, 1967) (see text). The error bars of curves $a, b$, and $c$ represent the range of several measurements. The error bars on $d$ represent the square root of the sum of the square of the error bars of $b$ and $c$. (Since Fig. 2 is a logarithmic plot, the error bars appear larger in $d$ than they would on a linear plot.)

The second question (ii), of the shape of the action spectrum of the light-adapted state, was tested with the results shown in Fig. 2a. The light-adapted state was induced by two different methods, both giving the same action spectrum within experimental errors. The first method was to bleach the "rod component" in vivo by four intense blue flashes (filters CS-1-57 and CS-5-60 $\left(\lambda_{\max }=420 \mathrm{~nm}\right)$, initial FPV amplitude of about $\left.200 \mu \mathrm{V}\right)$ and then to wait for about $10 \mathrm{~min}$ for the regeneration of the "cone component" that was 
bleached by the blue flashes. The action spectra was then recorded with different wavelengths spaced at 2-min intervals. The second method was to bleach the living eye with continuous white light and $5 \mathrm{~min}$ later remove the eye, and after mounting the isolated intact eye make the measurements. The amplitudes were found to be independent of the sequence in which the wavelengths were presented in making the measurement. (See Fig. 2a.) This action spectrum is in fair agreement with EBREY and CONE's (1967) action spectrum for the intact frog eye at $12^{\circ} \mathrm{C}$ (also shown on Fig. 2a). The smooth curve in Fig. 2a is from GranIT's (1941) cone (light-adapted) measurements of the action spectrum for "retinal spike frequency". The agreement of the data points with his curve is quite good, especially when we consider the difference in methods and the fact that there is a photostable component with a flat action spectrum (EBREY and CONE, 1967), included in this measurement that would broaden the action spectrum. There is also good agreement with ChapMan (1961), with recent work by GoRDON (1967) on the action spectrum of the cone ERG, and with LIEBMAN's (1968) spectrophotometry measurements. This seems to show that this "regenerable" component is from the regeneration of the cone pigments. The dark-adapted action spectrum is also shown in Fig. 1a, with a possible difference at the short wavelengths.

\section{APPARENT ROD COMPONENT}

The second hypothesis (B) suggested by Fig. 1a, that the initial decrease due to the sequence of white flashes is possibly the bleaching of rods, would lead to the following two predictions: (i) if blue flashes (filters CS-5-60 and CS-1-69, peaked at $420 \mathrm{~nm}$, width $350-520 \mathrm{~nm}$ at the 10 per cent level) are used, instead of white, a larger decrease of the original amplitude (about $100 \mu \mathrm{V}$ ) should be observed, and if red light (filters CS-1-57 and CS-2-63, peaked at $610 \mathrm{~nm}$, width $590-730$ at the 10 per cent level) is used a smaller decrease should be observed, since the "green rods" and "pink rods" of the frog have been shown to absorb broadly in the blue with maximum absorbance near $433 \mathrm{~nm}$ and $502 \mathrm{~nm}$ respectively (DARTNALL, 1967; DARTNALL, 1953). (ii) The difference between the darkadapted and light-adapted FPV action spectra of the eye should represent this apparent rod component that is bleached during the light-adaptation.

The first prediction (i) was tested in vivo and the results are shown in Fig. 3 using a fixed pupil. There is indeed about 30 per cent initial fast decrease with the blue bleaches and no observable initial fast decrease with the red. This experiment has been previously reported by the author (TAYLOR, 1968). Using the excised retinas gives similar results, except that the decrease in the blue is larger as expected since the photostable component is removed when the pigment epithelium is separated from the retina (see the wave form in Fig. 3 of the first and fourth FPV's in the blue from the excised retina). The component from the pigment epithelium was about the same percentage of the FPV for both the blue and red flashes. (See caption Fig. 3.) A second experiment was necessary to show that the blue flashes were not functionally damaging the source of the red responses. This experiment was to alternate red and blue flashes into the same living eye. ${ }^{2}$ The resuilts of this experiment showed that FPV from the red flashes had a slowly decreasing amplitude similar to Fig. $3 b$ throughout the sequence, while the FPV from the blue flashes decreased more rapidly. This showed that the blue flashes were not simply functionally damaging a single generating source, but that there must be at least two independent sources generating the FPV.

\footnotetext{
An experiment kindly suggested by Dr. R. A. Cone (private communication).
} 


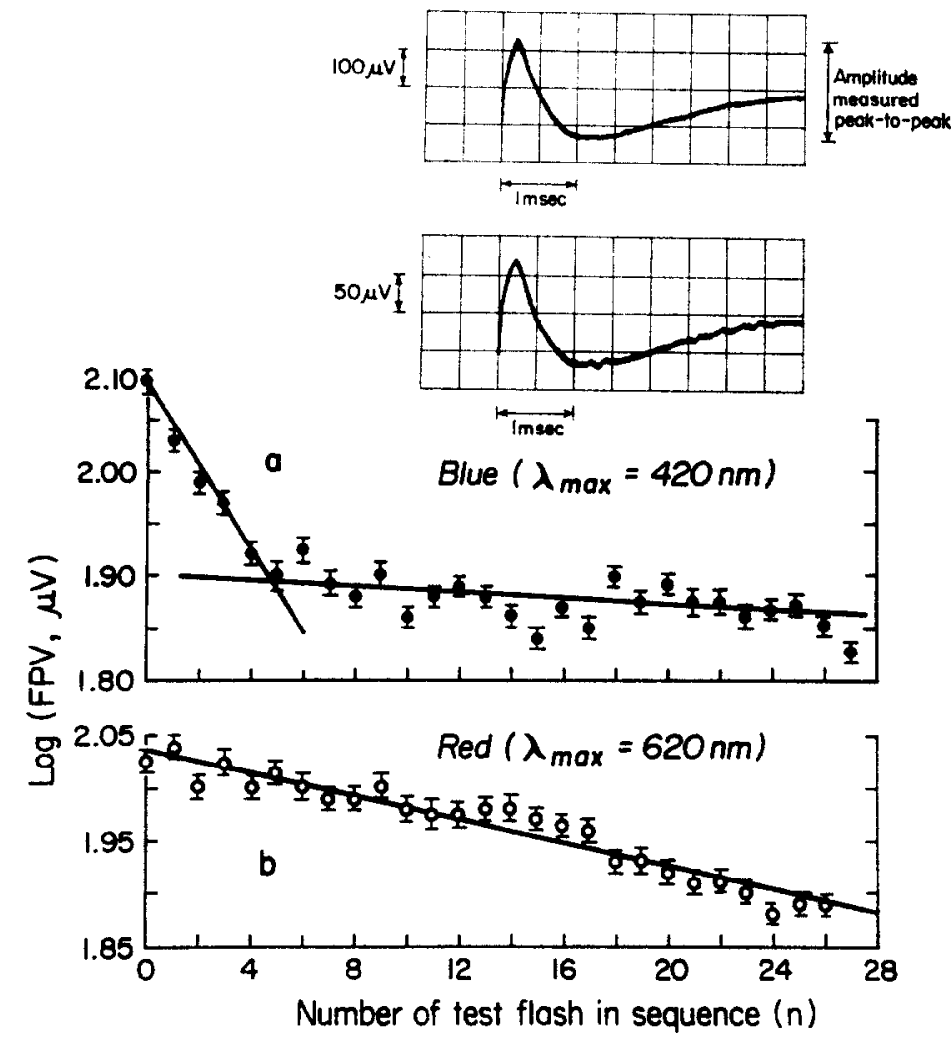

Fig. 3. (a) Changes in FPV amplitudes in vivo from a sequence of equally spaced test flashes in one eye. Using a blue light sequence, the initial rapid drop in the FPV amplitude from the first 6 to 8 flashes indicated a loss of a blue sensitive component of the FPV, representing about 30 per cent of the response in the blue (peaked near $420 \mathrm{~nm}$, see text).

(b) Similar changes in the FPV amplitude from a sequence of red flashes (peaked near $620 \mathrm{~nm}$, see text) in vivo made no initial drop of amplitude, but only a steady loss of less than 1 per cent per flash, indicating that the blue-sensitive component is not being readily bleached by red flashes. The error bars represent the uncertainty of a single voltage measurement in both $a$ and $b$. The initial FPV amplitudes were about $100 \mu \mathrm{V}$ for both $a$ and $b$. The photostable component represents $25 \pm 5$ per cent of the initial blue response and $20 \pm 5$ per cent of the initial red response. The inserted curves show a tracing of the first and fourth FPV from a sequence of more intense blue flashes in the excised retina at $22^{\circ} \mathrm{C}$, showing that the large drop in amplitude involves no change in waveform. The initial rapid negative deflection, from the zero line downward, is a stimulus artifact.

The decrease in the apparent rod component in vivo per flash (Figs. 1a and 3a) is apparently larger than the fraction of rhodopsin bleached as reported by GoLDSTEIN (1967) for similar FPV amplitudes in the excised retinas. This difference might be due to local shunting in the intact eye, requiring a larger bleach per flash to give similar FPV amplitudes as recorded for the intact retina.

The second prediction (ii), a possible difference spectrum representing a rod component, was not testable on the living preparation because of the large error bars (see Fig. 2 a) but it was found possible to test it on the excised retina. Excising the retina also has the advantage of removing the black pigment epithelium and its photostable FPV component. A central $3 \mathrm{~mm}$ disk cut out of the excised retina was used since this portion 
gave a more repeatable action spectrum (perhaps because the ratio of rods to cones may change somewhat in different parts of the retina). This central area has been studied with the electron microscope by NiLsson (1964).

Since Fig. 3a shows that blue flashes change the FPV amplitude of the dark-adapted state, only the first (or second) FPV at the short wavelengths were used in obtaining the dark-adapted action spectra. Therefore about 10 retinas were used, each contributing data at 3-5 different wavelengths. The data from different eyes were standardized by normalizing the responses at $563 \mathrm{~nm}$ since there is no apparent decrease in the FPV amplitude during the light-adaptation at this wavelength. The dark-adapted action spectrum so obtained is shown in Fig. 2b, with the dotted curve drawn through the points below $520 \mathrm{~nm}$. The light-adapted state was induced by intense blue flashes similar to the method used on the intact eye. The action spectrum is shown in Fig. $2 \mathrm{c}$ and gives a good fit to the dot-dashed curve from GraNIT (1941), and the dotted curve is added at short wavelengths.

There is a difference between this dark-adapted spectrum and the light-adapted spectrum in the blue range and this difference is plotted in Fig. 2d. It is seen that although the experimental errors are relatively large, this difference spectrum appears to be fairly uniform from 420 to $500 \mathrm{~nm}$. As had been indicated, this difference spectrum might contain contributions from both pink and green rods. The relative contributions of pink and green rods to the FPV is not known, as well as any possible short wavelength cones that may have a slow recovery rate. But if one combines the absorption spectrum of the blue pigment extracted by DARTNALL (1967) peaking at $433 \mathrm{~nm}$ (presumably from green rods), and the rhodopsin absorption spectrum (DARTNALL, 1953) peaking at $502 \mathrm{~nm}$ (from the pink rods), in the ratio of say $1: 2$, the dashed curve of Fig. $2 \mathrm{~d}$ is calculated, which fits this FPV difference spectrum within the considerable uncertainties of the observed points. Both predictions with regard to an apparent rod component therefore seem to be verified. A third piece of supporting evidence is that the bleached portion of the FPV does not regenerate in the 10-15 min during the recording of the action spectrum.

There are two other possibilities that could cause this preferential decrease in the blue, but they can probably be excluded. (1) An artifact at the electrode contact which is blue sensitive could give similar results; however the decrease in the blue is seen in both the intact eye and the excised retina, and under different experimental arrangements. (2) If the bleaching of a single pigment formed photosensitive intermediates as observed for rhodopsin (ARDEN, 1966; CONE, 1967; PAK, 1967; EBREY, 1968), they could possibly contaminate the FPV in the blue; however there is no change of wave-form of the FPV from either the blue or red flashes (wave-forms shown in Fig. 3) in agreement with GoLdsTEIN (1967, 1968). Another critical experiment is that if the living eye is bleached with white light 5 min before excising the retina, then no decrease in the FPV is observed from a sequence of blue flashes into the excised retina.

\section{CONCLUSION}

The results of this work indicate that in Rana pipiens there appear to be at least two components of the FPV in the excised retina and three components in the intact eye (rod, cone, and a photostable component from the pigment epithelium), with the major contribution from the cones. This is surprising since the cone pigment is thought to be only a small fraction of the total visual pigment as pointed out by GolDsteIN $(1967,1968)$. (It should be noted that what is called the apparent rod component here does not exclude 
a blue absorbing cone that recovers slower than the cones that show the rapid recovery of Fig. 1.) The evidence for the cone component (about 55 per cent in the intact eye for a white light flash) is (a) the very rapid regeneration (Fig. 1b) which is well fitted by the curve calculated from a first-order equation, and (b) the light-adapted (continuous white bleach or blue flashes) action spectrum peaking near $570 \pm 20 \mathrm{~nm}$ (Fig. 2) in agreement with earlier light-adapted frog data. The observations supporting an apparent rod component (about 15 per cent) are: (a) there is a difference spectrum between the FPV action spectra for the light-adapted and dark-adapted excised retina and it can be approximated by combining the previously measured spectral sensitivities of the pigments from pink and green rods (Fig. 2d), (b) the apparent rod component is readily bleached by blue flashes (peaking at $420 \mathrm{~nm}$ ), white flashes or a continuous white light, but is not readily bleached by red flashes (peaking at $620 \mathrm{~nm}$ ), and (c) this component that is bleached with lightadaptation (blue flashes or white flashes) does not regenerate in 10-15 min during the action spectrum measurements or the measurements of Fig. 1.

\section{DISCUSSION}

The difference spectrum was not found by GoLDsTEIN (1967), who reported similar action spectra for the light-adapted and dark-adapted states; however, this may be due to the fact that he has only one data point for the light-adapted curve below $490 \mathrm{~nm}$. GoLDstern $(1967,1968)$ also used the intact excised retina while the present work was on only the central portion of the excised retina. In addition, the dark-adapted action spectra here represent data recorded only from the first and second flashes at wavelengths less than $540 \mathrm{~nm}$, while GoLDSTEIN (1967) recorded FPV amplitudes in a sequence of five flashes from short to long wavelengths (or vice versa), and averaged the amplitudes at each point, possibly bleaching out part of the apparent rod component during his experiment.

His regeneration measurements in the excised retina also showed a considerably slower recovery time than reported here and apparently cannot be approximated with a theoretical first-order equation possibly because the retina had been excised. However, by using a background red bleach, GoLDSTEIN (1968) was able to separate a component with an action spectrum similar to Fig. $2 \mathrm{~d}$ but representing a slightly larger percentage of the darkadapted signal. He concluded that this component was probably from rhodopsin or green rods. He also gives evidence of a possible short wavelength component from cones. LIEBMAN (1968) has recently observed spectroscopically a cone with an absorption spectrum indistinguishable from rhodopsin.

Both of these studies of the FPV of the frog (Rana pipiens) therefore indicate that an apparent rod and a cone component of the FPV seem to be separable in the mixed eye or retina of the frog. This work seems to go beyond Goldstein's in showing that: (1) the FPV regeneration experiment seems to be a new and simple method for measuring cone regeneration rates in the living eye, (2) this regeneration curve for the frog eye in vivo can be fitted by a first-order rate equation with a half-life of $22 \pm 8 \mathrm{sec}$ at about $22^{\circ} \mathrm{C}$, and (3) the living eye and excised retina (Fig. 2) have very similar action spectra. The action spectrum for the living eye appears slightly broader, but this can be explained by the loss of the photostable component when the pigment epithelium is removed

Why the cones appear to dominate the FPV is not yet understood. The apparent rod component might be separated further by using a selective green bleach, as has been done previously on extracted frog rod pigments (DARTNALL, 1967). 
Acknowledgement-This study was carried out in the laboratory of Dr. J. R. PLATT and was supported by PHS Grant GM-14035. I thank Dr. T. G. EBREY for helping initiate this study, and Drs. ALPERN, CONE, Goldstein, GrEen, and other colieagues for helpful criticism and discussions.

\section{REFERENCES}

ARDEN, G. B., IKEDA, H. and SIEGEL, I. (1966). Effects of light-adaptation on the early receptor potential. Vision Res. 6, 357-371.

Brown, K. T. and Murakami, M. (1964). A new receptor potential of the monkey retina with no detectable latency. Nature, Lond. 201, 626-628.

Brown, K. T. (1965). An early potential evoked by light from the pigment epithelium-choroid complex of the eye of the toad. Nature, Lond. 207, 1249-1253.

CoNs, R. A. (1964). Early receptor potential of the vertebrate retina. Nature, Lond. 204, 736-739.

CONE, R. A. (1965). The early receptor potential of the vertebrate eye. Cold Spring Harb. Symp. quant. Biol. 30, 483-491.

CONE, R. A. (1967). Early receptor potential: Photoreversible charge displacement in rhodopsin. Science, N.Y. 115, 1128-1131.

Chapman, R. A. (1961). Spectral sensitivity of single neural units in the bullfrog retina. J. opt. Soc. Am. $51,1102-1112$.

DaRTNall, H. J. A. (1953). The interpretation of spectral sensitivity curves. Br. med. Bull. 2, 24-30.

DARTNAll, H. J. A. (1967). The visual pigment of the green rods. Vision Res. 7, 1-16.

DONNER, K. O. and Rusrron, W. A. H. (1959). Rod-cone interaction in the frog's retina analysed by the Stiles-Crawford effect and by dark adaptation. J. Physiol. 149, 303-317.

Errey, T. G. and Cone, R. A. (1967). Melanin, a possible pigment for the photostable electrical response of the eye. Nature, Lond. 213, 360-362.

ErREY, T, G. (1968). The thermal decay of the intermediates of rhodopsin in situ. Vision Res. 8, 965-982.

GoLDSTEIN, E. B. (1967). Early receptor potential of the isolated frog (Rana pipiens) retina. Vision Res. 7, 837-845.

Goldstern, E. B. (1968). Visual pigments and the early receptor potential of the isolated frog retina. Vision Res. 8, 953-964. I am indebted to Dr. Goldstein for kindly sending me a copy of this manuscript.

GoRdon, J. (1967). ERG spectral sensitivity of the frog (Rana pipiens). Master's thesis, Brown Univ., Prov., R.I.

GRANrT, R. (1941). Color receptors of the frog's retina. Acta physiol. scand. 3, 137-151.

HAons, W. A. and MCGAUGHY, R. E. (1967). Molecular and thermal origins of fast photoelectric effects in the squid retina. Science, $N, Y, 157,813-816$.

Liegman, P. A. and Entine, G. (1968). Visual pigments of frog and tadpole (Rana pipiens). Vision Res. 8, 761-776.

Nusson, S. E. G. (1964). An electron microscopic classification of the retinal receptors of the leopard frog (Rana Pipiens). J. ultrastruct. Res. 10, 390-416.

PAK, W. L. and EBREY, T. G. (1966). The early receptor potentials of rods and cones in rodents. J. gen. Physiol. 49, 1199-1208.

PAK, W. L. and BOEs, R. J. (1967). Rhodopsin: Responses from transient intermediates formed during its bleaching. Science, $N . Y .155,1131-1133$.

Rusrton, W. A. H. (1963). Cone pigment kinetics in the pronatope. J. Physiol. 168, 374-388.

Rushton, W. A. H. and HenRY, G. H. (1968). Bleaching and regeneration of cone pigments in man. Vision Res. 8, 617-631.

TAYLOR, J. W. (1968). The early receptor potential of the living frog (Rana pipiens) eye. (Abstract). Fifth International Congress on Photobiology.

WEALE, R. A. (1959). Photo-sensitive reactions in fovea of normal and cone-monochromatic observers. Optica Acta 6, 158-174.

ZEwI, M. (1939). The infiuence of temperature on the regeneration of visual purple. Acta Soc. Sci. Fenn. N.S.B. 2, 1-7.

\footnotetext{
Abstract-Differential bleaching and regeneration effects permit the separation of three components in the Fast Photovoltage (FPV) obtained following a millisecond flash of light on the eye of the frog. The action spectra and recovery characteristics indicate that the major component of the FPV is from cones, with a sensitivity peak near $570 \pm 20 \mathrm{~nm}$ and a recovery half-life in vivo of $22 \pm 8$ sec. An apparent rod component is separated by selective bleaching. The third component of the FPV is photostable and has been previously reported from the pigment epithelium.
} 
Résumé-Les effets différentiels de décoloration et de régénération permettent de séparer les trois composantes du Photovoltage rapide (FPV) qui suit dans l'oeil de la grenouille un éclair de lumière de $1 \mathrm{msec}$. Le spectre d'action et les caractéristiques de la récupération indiquent que la composante principale du FPV provient des cônes, avec un maximum de sensibilité près de $570 \pm 20 \mathrm{~nm}$ et une période de récuperation de $22 \pm 8 \mathrm{sec}$. On sépare grâce à une décoloration sélective une composante qui provient apparemment des bâtonnets. La troisième composante du FPV est photostable et a déjà été décrite comme provenant de l'épithélium pigmentaire.

Zusammenfassung-Differentialbleichung und Regenerationseffekte ermöglichen es drei Teile des Schnellichtpotentials (SLP), das durch einen Millisekundenlichtblitz im Froschauge ausgelöst wird, zu unterscheiden. Die Aktionsspektren und Regenerationskennzeichen zeigen an, dass der grössere Teil des SLP von Zapfen mit einem Empfindlichkeitsmaximum von $570+20 \mathrm{~nm}$ stammt, die Halbzeit der Regeneration ist in vivo $22 \pm 8 \mathrm{sec}$. Ein scheinbarer Stäbchenanteil ist durch Differentialbleichung noch zu erkennen. Der dritte Teil des SLP ist lichtunempfindlich und war schon früher dem Pigmentepithel zugeschgrieben worden.

Резюме - Различные эффехты, наблюдаемые при выцветании и регенерации зрительных пигментов, позволяют разделить на три компонента быстрые фотопотенщиалы (БФП), возникајошие при воздействии на глаз лягушки вспышки света длящейся миллисекунду. Спектры действия и характеристики восстановления указьвают на то, что главный компонент БФП генерируется колбочками с максимумом чувствительности охоло $570 \pm 20$ нм с полупериодом восстановления in vivo в $22 \pm 8$ сек. Путем селективного обесцвечивания выделен очевидно палочковый компонент. Третий компонент БФП фотостабилен и о нем сообщалось ранее, что он возникает в питментном эпителии. 